\title{
Intrauterine transplantation of autologous bone marrow derived mesenchymal stem cells followed by conception in a patient of severe intrauterine adhesions
}

\author{
Yong Zhao, Aiming Wang", Xiaorong Tang, Min Li, Ling Yan, Wei Shang, Meizhu Gao \\ Department of Obstetrics and Gynecology, Navy General Hospital, Chinese People's Liberation Army (PLA), Beijing, China \\ Email: stampzhy@126.com,
}

Received 13 March 2013; revised 15 April 2013; accepted 22 April 2013

Copyright (C) 2013 Yong Zhao et al. This is an open access article distributed under the Creative Commons Attribution License, which permits unrestricted use, distribution, and reproduction in any medium, provided the original work is properly cited.

\begin{abstract}
On a woman with severe intrauterine adhesions, hysteroscopy followed by cyclical hormone replacement therapy was tried for $\mathbf{5}$ months, for development of the endometrium. When this failed, autologous stem cells were tried as an alternative therapy. Adult autologous bone marrow mesenchymal stem cells isolated from patient's own bone marrow and were cultured and placed in the endometrial cavity under ultrasound guidance after curettage. Patient was then given cyclical hormonal therapy. Endometrium was assessed intermittently using ultrasound. Three months later, endometrium partly recovered with improved ultrasonic echo. This resulted in spontaneous pregnancy followed by confirmation of gestational sac, yolk sac, and primitive heart tube pulse on ultrasound. Autologous bone marrow derived mesenchymal stem cells could regenerate injured endometrium not responding to conventional treatment and can be used as an alternative in females with severe Asherman's syndrome.
\end{abstract}

Keywords: Intrauterine Adhesions; Asherman's Syndrome; Bone Marrow Derived Mesenchymal Stem Cells; Pregnancy

\section{INTRODUCTION}

Intrauterine adhesions are mutual adhesion of the uterine cavity caused by various factors leading to endometrial damage, also called Asherman syndrome [1]. It can lead to adverse outcomes such as infertility, recurrent miscarriage, amenorrhea, pelvic pain, and seriously affect the

\footnotetext{
"Funds: Ministry of national science and technology "Twelfth FiveYear Plan” science and technology support program (2012BAI32B05). "Corresponding author.
}

reproductive health of women of reproductive age. In recent years, with the increase of intrauterine operation, the incidence of intrauterine adhesions is rising. Current therapy strategy for intrauterine adhesions is separation of adhesions, removal of fibrotic tissue using hysteroscopic surgery, adjuvant estrogen or/and progestin therapy after operation. But still a large number of patients failed after repeated surgical treatment, with adhesions reformation in inuterine cavity [2]. In this case report, we describe a case of Asherman's syndrome treated with adult autologous bone marrow mesenchymal stem cells for endometrial regeneration that resulted in spontaneous conception.

\section{CASE REPORT}

In March 2011, a 36-year old female patient came to see a doctor in the reproductive medical center of our hospital for chief complaint as she didn't get pregnant with oligohypomenorrhea seven months after stopping contraception methods. The patient had been married for ten years and lived with her husband together normally. She had four times medical abortions because of accidental pregnancy. The patient was given uterine curettage because of Early Embryonic Death in May 2009, December 2009 and August 2010 separately. There was progressive oligohypomenorrhea after surgery and the menstrual cycle was completed ahead of time. The menstrual blood loss was about one third of that before last abortion. There was only brown secretion without dysmenorrhea during menstrual period which lasts 5 - 7 days. The hormone level was normal when she came to see a doctor in March 2011. Routine Semen Analysis and sperm DNA integrity test of her husband was normal too. Hormone replacement therapy was given on the second day of menses in May 2011. Progynova (estradiol valerate) was administered orally once a day for 26 days. At the sev- 
enteenth day of progynova administration progesterone capsule was administered orally once a day for 10 days and aspirin was continuously administered orally once a day. The endometrial thickness was 4 millimeters under reexamination of B type ultrasound. Hysteroscopy and adhesion lysis were given to the patients in June 2011 because of the invalid hormone adjustment. The endometrium was thin and large area fibrosis of the uterine cavity was found in the operation (Figure 1). Hormone replacement therapy was given to the patient after surgery but there was no improvement in the endometrium under the B type ultrasound. The endometrial thickness was 4 millimeters at maximum. There was no menses in October 2011 and November 2011 separately.

Because of the invalid conventional therapy, after getting the informed consent of the patient, bone marrow puncture was given to the patient and 30 milliliters autologous bone marrow were collected from the patient and was used for abstraction, separation and culture of autologous mesenchymal stem cells. At the second day of the menses, the patient was given hysteroscopy, adhesion lysis and mesenchymal stem cells transplantation under general anesthesia. Adhesive uterine cavity was separated in the operation. After the shape of the uterine cavity was normal, the surgeon underlay the cervix, use the implantation tube to push 1 milliliters $\left(1 \times 10^{7}\right)$ autologous mesenchymal stem cell to the uterine cavity until the mesenchymal stem cells arrived at the cervix under the monitoring of abdominal B ultrasound and withdrew the implantation tube two minutes later.

The hormone replacement therapy was given to the patient in artificial cycle for three menstrual cycles after surgery. At the same time 75 milligrams aspirin were given to the patient. At the second day of the first and second menstrual cycle 6 milligrams estradiol valerate (progynova) were given to the patient orally once a day for 25 days. At the sixteenth day of progynova administration 20 milligrams dydrogesterone (duphaston) were

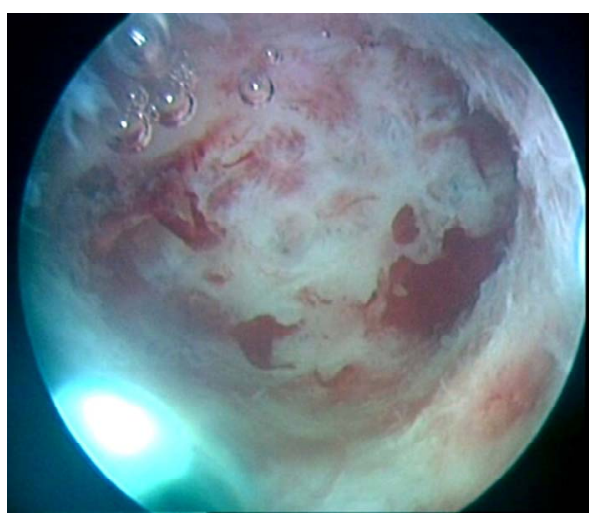

Figure 1. Hysteroscopic picture indicating a large number of fibrotic tissues covering the endometrial surface. given to the patient orally once a day for 10 days. The treatment was stopped for the menses. There was a little bit of improvement in the endometrium under B ultrasound and at the third day of the third menstrual cycle 6 milligrams estradiol valerate (progynova) were given to the patient orally once a day for 30 days. The endometrial thickness was 2.5 millimeters and partial endometrium was $B$ type at the eighth day of the menses under B type ultrasound. The doctors also found that there small fluid chamber with obscure endometrium profile and the lower segment of the uterine cavity was slightly separated. The white pill of femonston (Complex Packing Estradiol Tablets/Estradiol and Dydrogesterone Tablets) was given to the patient in the vagina for 24 days and the grey pill of femonston was given to the patient in the vagina for 14 days. Hormone intervention was not given in the fourth menstrual cycle. At the ninth day (April 25, 2012) of the menses, the thickness of the uterine fundus was 3.2 millimeters and the endometriums of the lower uterine cavity and the left uterine fundus were thin (Figure 2). Patient was instructed to have intercourse based on monitoring ovulation. At the 37th day of the menses, the urine pregnancy test was positive and the concentration of blood HCG was $686 \mathrm{mIU} / \mathrm{ml}$. At the same time the concentration of estradiol was $325 \mathrm{pg} / \mathrm{ml}$ and the concentration of progesterone was $15.2 \mathrm{ng} / \mathrm{ml}$. All the three data indicated that the patient was pregnant. At the 52nd day of the menses, there was early pregnancy in the uterine cavity and the size of gestational sac was $1.9 \times 3.8 \times 1.2$ under B type ultrasound. The diameter of the yolk sac was 0.32 centimeters. The length of fetal bud was 0.3 centimeters. Embryonic heartbeats could be seen (Figure 3).

\section{DISCUSSION}

This was a successfully treated case of infertility with severe Asherman's syndrome after several times artificial abortion and arrested intrauterine pregnancy with

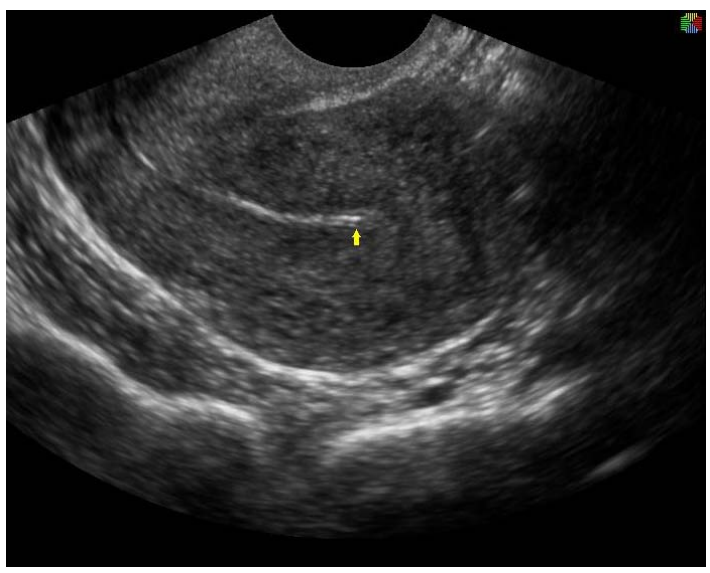

Figure 2. Ultrasound image indicating endometrial recovery (arrow). 


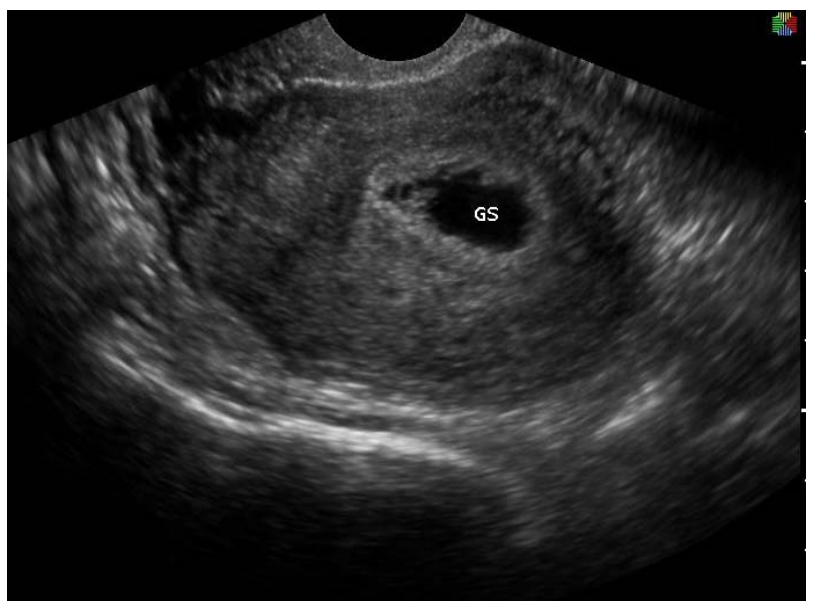

Figure 3. The ultrasound image of intrauterine fetus (8 weeks).

curettage, using autologous bone marrow derived mesenchymal stem cells (BM-MSC). Stem cell is regenerative cells in a variety of tissues and degenerative diseases, is the basis of normal tissue repair. Stem cells derived from bone marrow, umbilical cord, fat and amniotic have been extensive studied in research of clinical application [3]. Endometrial repair in the menstrual cycle is essential for fertility, which rely mainly on endometrial stem cells in the basal layer [4]. Recent studies have found that donor bone marrow-derived stem cells can be detected in fe- male endometrium after bone marrow transplant, suggesting that nonuterine stem cells contribute to the regeneration of endometrial tissue [5]. Similar phenomenon was also observed in animal experiments, endometrium of female mice transplanted male mice bone marrow-derived stem cells can be detected the y-chromosome positive cells [6]. This made it possible that autologous bone marrow mesenchymal stem cells can be used in treatment of endometrial injury [7].

The bone marrow is the body's repository of stem cells, stem cells can rapidly mobilized and homed to the site of injury to repair tissue. Autologous stem cells by bone marrow aspiration are an ideal source of stem cells, with little risks and trauma. Autologous bone marrow mesenchymal stem cells, isolated, cultured, amplified and then transplanted to patients itself, were more conducive to application without HLA match test and ethical risk.

Hysteroscopy was given to the patient at the second day of the menstrual cycle and the adhesive and fibrotic tissues were separated from the uterus to expose the basal lamina of the endometrium. The fresh surface of a wound would be formed. Intrauterine transfer was given to the patient when the number of autologous bone marrow mesenchymal stem cells was $1 \times 10^{7}$. The endometrium was easy to repair itself under the action of the estrogen after surgery and then the stem cells could be induced to home to the injured portion. Previous study demonstrated that estrogen was essential to induce the proliferation of the stem cells in the endometrium and the endometrium was regenerated under the action of the estrogen [8]. In 2011, there was a case in India that the patient with severe intrauterine adhesion was cured by autologous bone marrow angioblastic stem cells transplantation and then the patient was successfully pregnant [9].

Severe intrauterine adhesions, especially patients after repeated surgery and conventional treatment failure, is lack of more effective treatment [2]. With the advances of endometrial stem cell research, more and more attention focus on the role of endometrial stem cells in endometrial regeneration [7], but the mechanism is not yet very clear. Intrauterine transplantation of stem cells act directly as endometrial stem cells to repair, or as a secretory function cells to secrete large amounts of cytokines stimulating the regeneration of endometrial cells still need further research. The patients in this report, failing to conception after repeated surgical therapy, succeed to pregnant with autologous bone marrow mesenchymal stem cell transplantation. Although further clinical observation still needs to perform, it provides a new treatment option for severe intrauterine adhesions.

\section{REFERENCES}

[1] Deans, R. and Abbott, J. (2010) Review of intrauterine adhesions. The Journal of Minimally Invasive Gynecology, 17, 555-569. doi:10.1016/j.jmig.2010.04.016

[2] March, C.M. (2011) Management of Asherman's syndrome. Reproductive BioMedicine Online, 23, 63-76. doi:10.1016/j.rbmo.2010.11.018

[3] Meng, X., Ichim, T.E., Zhong, J., et al. (2007) Endometrial regenerative cells: A novel stem cell population. Journal of Translational Medicine, 5, 57. doi:10.1186/1479-5876-5-57

[4] Gargett, C.E. and Ye, L. (2012) Endometrial reconstruction from stem cells. Fertility and Sterility, 98, 11-20. doi:10.1016/j.fertnstert.2012.05.004

[5] Taylor, H.S. (2004) Endometrial cells derived from donor stem cells in bone marrow transplant recipients. Journal of American Medical Association, 292, 81-85. doi:10.1001/jama.292.1.81

[6] Du, H. and Taylor, H.S. (2007) Contribution of bone marrow-derived stem cells to endometrium and endometriosis. Stem Cells, 25, 2082-2086. doi:10.1634/stemcells.2006-0828

[7] Morelli, S.S., Yi, P. and Goldsmith, L.T. (2012) Endometrial stem cells and reproduction. Obstetrics and Gynecology International, 2012, Article ID: 851367.

[8] Hyodo, S., Matsubara, K., Kameda, K., et al. (2011) Endometrial injury increases side population cells in the uterine endometrium: A decisive role of estrogen. The Tohoku Journal of Experimental Medicine, 224, 47-55. doi:10.1620/tjem.224.47 
[9] Nagori, C.B., Panchal, S.Y. and Patel, H. (2011) Endometrial regeneration using autologous adult stem cells followed by conception by in vitro fertilization in a pa- tient of severe Asherman's syndrome. Journal of Human Reproductive Sciences, 4, 43-48.

doi:10.4103/0974-1208.82360 